\title{
Effects of 4 weight-loss diets differing in fat, protein, and carbohydrate on fat mass, lean mass, visceral adipose tissue, and hepatic fat: results from the POUNDS LOST trial $^{1-3}$
}

\author{
Russell J de Souza, George A Bray, Vincent J Carey, Kevin D Hall, Meryl S LeBoff, Catherine M Loria, Nancy M Laranjo, \\ Frank M Sacks, and Steven R Smith
}

\begin{abstract}
Background: Weight loss reduces body fat and lean mass, but whether these changes are influenced by macronutrient composition of the diet is unclear.

Objective: We determined whether energy-reduced diets that emphasize fat, protein, or carbohydrate differentially reduce total, visceral, or hepatic fat or preserve lean mass.

Design: In a subset of participants in a randomized trial of 4 weightloss diets, body fat and lean mass $(n=424$; by using dual-energy X-ray absorptiometry) and abdominal and hepatic fat ( $n=165$; by using computed tomography) were measured after 6 mo and $2 \mathrm{y}$. Changes from baseline were compared between assigned amounts of protein (25\% compared with $15 \%$ ) and fat (40\% compared with $20 \%$ ) and across 4 carbohydrate amounts (35\% through 65\%).

Results: At $6 \mathrm{mo}$, participants lost a mean $( \pm \mathrm{SEM})$ of $4.2 \pm 0.3 \mathrm{~kg}$ (12.4\%) fat and $2.1 \pm 0.3 \mathrm{~kg}(3.5 \%)$ lean mass (both $P<0.0001$ compared with baseline values), with no differences between $25 \%$ and $15 \%$ protein $(P \geq 0.10), 40 \%$ and $20 \%$ fat $(P \geq 0.34)$, or $65 \%$ and $35 \%$ carbohydrate $(P \geq 0.27)$. Participants lost $2.3 \pm 0.2 \mathrm{~kg}$ (13.8\%) abdominal fat: $1.5 \pm 0.2 \mathrm{~kg}(13.6 \%)$ subcutaneous fat and $0.9 \pm 0.1 \mathrm{~kg}(16.1 \%)$ visceral fat (all $P<0.0001$ compared with baseline values), with no differences between the diets $(P \geq 0.29)$. Women lost more visceral fat than did men relative to total-body fat loss. Participants regained $\sim 40 \%$ of these losses by $2 \mathrm{y}$, with no differences between diets $(P \geq 0.23)$. Weight loss reduced hepatic fat, but there were no differences between groups $(P \geq 0.28)$. Dietary goals were not fully met; self-reported contrasts were closer to $2 \%$ protein, $8 \%$ fat, and $14 \%$ carbohydrate at 6 mo and $1 \%, 7 \%$, and $10 \%$, respectively, at $2 \mathrm{y}$.
\end{abstract}

Conclusion: Participants lost more fat than lean mass after consumption of all diets, with no differences in changes in body composition, abdominal fat, or hepatic fat between assigned macronutrient amounts. This trial was registered at clinicaltrials.gov as NCT00072995. Am J Clin Nutr 2012;95:614-25.

\section{INTRODUCTION}

Many trials of dietary approaches to weight loss report primarily changes in total body weight and waist circumference because these are easily obtained proxy measures of total fat mass and abdominal fat. However the primary aim of any weight loss regimen is the reduction of fat mass rather than lean mass, and the measurement of total body weight change does not provide detailed information about relative changes in fat and lean mass.
Although studies have examined body-composition changes in response to energy-reduced diets (1), exercise $(2)$, or both $(3,4)$, only a few studies have directly compared changes in fat mass and lean mass in $\geq 2$ calorie-reduced diets that varied in macronutrient composition (5-8). In some studies (9-13), but not in others $(14,15)$, low-carbohydrate, high-protein diets resulted in preferential loss of fat and preservation of lean mass.

Visceral fat mass is closely related to the metabolic consequences of obesity (16-20), and excess visceral fat is commonly thought to release fatty acids into the portal vein, which leads to an accumulation of fat in the liver (hepatic fat). Few trials have directly measured changes in visceral or hepatic fat in response to weight-reducing diets $(3,21-24)$, and there remains debate about which, if any, diet or diets are most effective for visceral fat loss, with very sparse data on dietary treatments to reduce hepatic fat accumulation (23-25). Some studies have shown higher-protein, low-carbohydrate diets $(11,21,26)$ or pharmacologic weight-loss approaches (27) to result in greater visceral fat loss than have conventional energy-restricted diets. Smith and Zachweija (28) reviewed 23 studies that involved 599 participants and showed that several approaches to weight loss (eg, caloric restriction, pharmaceutical agents, bariatric surgery, or exercise) preferentially reduced visceral fat, and individuals lost more visceral fat if they carried higher amounts of total body fat at baseline. Hallgreen and Hall (29) used an allometric equation, which has traditionally been used to describe the growth of a body part as a function of total body size, to quantify the relation between changes in visceral fat and total fat during

\footnotetext{
${ }^{1}$ From the Department of Nutrition, Harvard School of Public Health, Boston, MA (RJdS and FMS); the Pennington Biomedical Research Center, Baton Rouge, LA (GAB and SRS); the Channing Laboratory (FMS, VJC, and NML) and Endocrine Division (MSL), Department of Medicine, Brigham and Women's Hospital and Harvard Medical School, Boston, MA; the Laboratory of Biological Modeling, National Institute of Diabetes and Digestive and Kidney Diseases, NIH, Bethesda, MD (KDH); and the National Heart, Lung, and Blood Institute, Bethesda, MD (CML).

${ }^{2}$ Supported by the National Heart, Lung, and Blood Institute (grant HL073286) and the General Clinical Research Center, NIH (grant RR02635).

${ }^{3}$ Address correspondence to GA Bray, 6400 Perkins Road, Baton Rouge, LA 70808. E-mail: brayga@pbrc.edu.

Received March 24, 2010. Accepted for publication November 15, 2011.

First published online January 18, 2012; doi: 10.3945/ajcn.111.026328.
} 
intentional weight loss. In their model, the change in visceral fat relative to the change in total-body fat mass was expressed as a function of the baseline ratio of visceral fat to fat mass. The authors (29) reported that changes in visceral fat mass were allometrically related to changes in fat mass during weight loss, regardless of sex or the approach used for weight loss.

The POUNDS LOST ${ }^{4}$ trial (www.clinical trials.gov; NCT00072995) was a 2-center study that examined changes in body composition over $2 \mathrm{y}$ in a large group of men and women who ate 1 of 4 prescribed diets that differed in fat, protein, and carbohydrate. This trial provided an opportunity to determine whether the macronutrient composition of an energy-restricted diet affected the reduction in total body fat, visceral abdominal fat, or hepatic fat or the preservation of lean mass.

\section{SUBJECTS AND METHODS}

The POUNDS LOST trial was a randomized clinical trial that compared the effects on body weight and composition of energyreduced diets that were low (20\% of energy) or high $(40 \%$ of energy) in fat, were average $(15 \%)$ or high $(25 \%)$ in protein, and provided carbohydrate intakes of $35 \%, 45 \%, 55 \%$, or $65 \%$ of energy, which were targets that are generally consistent with national guidelines to reduce chronic disease risk. The trial was conducted at the following 2 sites: the Harvard School of Public Health and BWH (Boston, MA) and the PBRC, Louisiana State University (Baton Rouge, LA). The National Heart, Lung, and Blood Institute project staff also participated. The methods of recruiting, major inclusion and exclusion criteria, and protocols of diet and exercise instruction have been described in detail previously (30). The study was approved by the human subjects committee at both institutions and by a data safety monitoring board appointed by the National Heart, Lung, and Blood Institute. All participants gave written informed consent to participate in the study.

\section{Participants}

To be eligible for the POUNDS LOST trial, participants had to be 30-70 y of age and have a BMI (in $\mathrm{kg} / \mathrm{m}^{2}$ ) between 25 and 40 . Major criteria for exclusion were the presence of diabetes or unstable cardiovascular disease, the use of medications that affect body weight, and insufficient motivation as assessed by interview and questionnaire. A random sample of $\sim 50 \%$ of the 811 enrolled participants in the POUNDS LOST trial were selected to undergo DXA scans for fat mass and lean mass at baseline and after $6 \mathrm{mo}$ and $2 \mathrm{y}$ of follow-up. Of these individuals, $\sim 50 \%$ were randomly assigned to receive CT scans for total abdominal fat, subcutaneous abdominal fat, and visceral fat at the same time points.

\section{Diet intervention}

The following 4 diets were tested in this study: 1) a low-fat, average-protein diet (20\% fat, $15 \%$ protein, and $65 \%$ carbohy-

\footnotetext{
${ }^{4}$ Abbreviations used: BWH, Brigham and Women's Hospital; CT, computed tomography; DXA, dual-energy X-ray absorptiometry; HU, Hounsfield units; PBRC, Pennington Biomedical Research Center; POUNDS LOST, Preventing Overweight Using Novel Dietary Strategies; RQ, respiratory quotient.
}

drate, 2) a low-fat, high-protein diet (20\% fat, $25 \%$ protein, and $55 \%$ carbohydrate), 3) a high-fat, average-protein diet (40\% fat, $15 \%$ protein, and $45 \%$ carbohydrate), and 4) a high-fat, highprotein diet (40\% fat, $25 \%$ protein, and $35 \%$ carbohydrate). Other goals for all diets were saturated fat $\leq 8 \%$, dietary fiber $\geq 20 \mathrm{~g} / \mathrm{d}$, and cholesterol $\leq 150 \mathrm{mg} / 1000 \mathrm{kcal}$. Low-glycemic index foods were used in all diets. Each participant's caloric target represented a 750-kcal/d deficit from estimated energy requirements, which were estimated from a resting metabolic rate at baseline as determined by indirect calorimetry with the Deltatrac II metabolic cart (Datex-Engstrom Corp).

\section{Measurements}

\section{Dietary intake and adherence}

Dietary intake was assessed in a random sample of $50 \%$ of participants by using a review of the 5-d diet record at baseline and a 24-h recall during a telephone interview on 3 nonconsecutive days at 6 mo and at 2 y (31). Biomarkers of nutrient intake were used to validate self-reported adherence to macronutrient targets as follows: HDL cholesterol for carbohydrate (32), urinary nitrogen excretion for protein (33), and RQ for fat (34).

\section{Body weight and composition}

Body weight was measured with calibrated hospital scales in the morning before breakfast and after urination with participants clothed in a hospital gown on 2 nonconsecutive days at baseline and at $6 \mathrm{mo}$ and $2 \mathrm{y}$. The mean number of days between measurements was $5 \mathrm{~d}$ for baseline, $10 \mathrm{~d}$ for $6 \mathrm{mo}$, and $9 \mathrm{~d}$ for $2 \mathrm{y}$. After an overnight fast, body composition was measured by DXA on a Hologic QDR 4500A bone densitometer (Hologic Inc) at both PBRC and BWH with the participant in the supine position and while wearing a hospital gown. Digital files from BWH were transferred to PBRC, reanalyzed by a single reader, and digitally transferred to the PBRC clinical database. Daily phantoms were used to ensure instrument stability over time. A 3-point body fat phantom was used to verify the accuracy of the 2 instruments across study sites; no correction was applied because the 2 instruments were well matched and stable over time. Fat mass and lean mass were calculated from percentage of body fat and body weight.

\section{Total, visceral, and subcutaneous abdominal fat}

Total, visceral, and subcutaneous abdominal fat volumes and masses were measured by CT scanning with either a General Electric High-Light computed tomographic scanner (General Electric) at BWH or a GE LightSpeed volume computed tomographic scanner (General Electric) at PBRC. Eight images were acquired every $10 \mathrm{~cm}$ across the abdomen with the L4-L5 vertebrae as the anatomic landmark 2 slices below and 5 slices above the L4-L5 vertebral interspace $(35,36)$. Cross-sectional areas of visceral and subcutaneous adipose tissue were measured on these 8 scans (Analyze), and the total volume was calculated from the sum of the individual slices as described by Kvist et al (37, 38). Reader variability (CV) averages were $0.9 \%$. A CT phantom was used to verify the accuracy of the 2 instruments across study sites; no correction was applied because the 2 instruments were well matched and stable over time. Digital files 
from BWH were transferred to PBRC and analyzed by a single reader and uploaded into the PBRC database.

\section{Hepatic fat}

As a direct measure of hepatic fat, images from the 8-slice CT scan were used to determine hepatic density (liver minus spleen density) in HU. An increase in hepatic density was indicative of a decrease in hepatic fat content. Previously, our group has compared this method with hepatic quantitative proton magnetic resonance spectroscopy on a 1.5-T magnetic resonance, and we showed high concordance $\left(r^{2}=0.81\right.$; unpublished observations, DE Larson-Myer, SR Smith, and BR Newcomer, 2009).

\section{Statistical analysis}

Analyses were performed with SAS software (version 9.2; SAS Institute). The level of significance for all tests was set to $P<0.05$. Baseline data are reported as means $\pm \mathrm{SD}$ for continuous variables and as counts (percentage) for nominal variables. Changes from baseline data are expressed as means \pm SEMs. Differences between sexes and completers and noncompleters at baseline were tested by using independent-samples $t$ tests for continuous variables and chi-square or Fisher's exact tests for nominal variables. Pearson's correlation coefficients were computed to examine relationships between baseline measurements of body composition and changes over time.

\section{Models}

Diet and sex effects. To determine whether changes over time differed by sex or macronutrient amount, the generalized linear model ANOVA was used with change scores (6-mo or 2-y value minus the baseline value) as dependent variables. Main effects in these models were protein amount (15\% or $25 \%$ ) and fat amount (20\% or $40 \%)$. We included baseline total mass as a covariate in DXA models and baseline total abdominal tissue mass in abdominal CT models. Baseline hepatic density was the covariate in hepatic density models. Other covariates in all models were site, age, and sex. Prespecified comparisons of interest (30) were high-protein (25\%) compared with average-protein (15\%) diets, high-fat $(40 \%)$ compared with low-fat $(20 \%)$ diets, and highcarbohydrate (65\%) compared with low-carbohydrate (35\%) diets and between men and women. When the generalized linear model ANOVA identified a between-groups difference, we determined which pairs of groups differed by using the TukeyKramer method. There were no significant interactions between protein and fat amounts in any of these models, which justified the analysis by factorial design.

Tests for trend across carbohydrate assignment and intake. We tested for a trend across the carbohydrate amount assigned (35-65\%) by using multiple linear regression. In these models, change score (6-mo or 2-y value) was the dependent variable, carbohydrate amount was the main continuous predictor, and baseline value, age, sex, and site were covariates.

Selectivity of visceral fat reduction. The relative change in visceral fat to total body fat was examined by using the methods proposed by Hallgreen and Hall (29). See "Supplemental data" in the online issue for a detailed description of the methods. Briefly, the outcome variable for this analysis was the allometric constant $k$ approximated by the regression coefficient of the $\Delta$ visceral fat $(\mathrm{kg}) / \Delta$ fat mass $(\mathrm{kg})$ ratio regressed on the baseline visceral fat $(\mathrm{kg}) /$ fat mass $(\mathrm{kg})$ ratio by means of no-intercept regression.

\section{Missing data}

The primary analysis in this trial was an intention-to-treat analysis. Long-term weight loss for individuals who dropped out early (after $\geq 6$ mo participation in the behavioral experiment) was imputed by using a weight regain rate of $0.3 \mathrm{~kg} / \mathrm{mo}$ after dropout (39). Regain was extrapolated from the time of dropout up to 6 mo or 2 y according to this rate, but regain was truncated at no change from baseline whenever the extrapolation would lead to a positive weight gain. When an individual's weight at dropout represented a gain in weight relative to weight at baseline, no additional gain was imputed, but the unfavorable gain was carried forward to 6 mo or 2 y as needed. Zero weight change was assumed for participants who did not return after enrollment (very early dropout; $n=21$ in the study). We applied the baseline body fat percentage to the imputed weight to estimate fat and lean mass at the missing time point. For individuals who were missing complete CT data at 6 mo or $2 \mathrm{y}$, baseline values replaced missing values of each abdominal fat compartment and hepatic density.

\section{Power}

The study had $80 \%$ power to detect a $0.7-\mathrm{kg}$ difference in totalbody fat loss and a $0.33-\mathrm{kg}$ difference in visceral fat loss as an effect of the amount of protein or fat in the diet over the 2-y period, with assumption of a dropout rate of $40 \%$.

\section{RESULTS}

\section{Participants}

At baseline, there were 424 DXA measurements (for 242 women and $182 \mathrm{men}$ ), complete abdominal fat CT data (total, visceral, and subcutaneous abdominal fat) for 165 participants (85\%; 91 women and 74 men), and CT liver and spleen density in 194 participants (113 women and 81 men) (Table 1). The main reasons that 29 individuals did not provided complete CT information at baseline were related to technical limitations of CT for measuring a large abdominal volume. Both the DXA and CT cohorts included proportionally more men than did the full cohort of 811 participants ( $45 \%$ compared with $35 \%$, respectively) but were distributed evenly across diet groups. DXA and CT cohorts had similar sex distributions and body weight and composition at baseline. The mean $( \pm \mathrm{SD})$ age of all participants was $52 \pm 9 \mathrm{y}$, with BMI of $33 \pm 4$. The bodycomposition cohorts were of similar BMI as individuals who were not selected but were between 2 and 4 y older.

See the supplemental figure under "Supplemental data" in the online issue for the flow of participants through the study. The cohorts that completed measurements at $6 \mathrm{mo}, 2 \mathrm{y}$, or both had similar sex distributions and body weight and composition at baseline compared with those who did not complete the study. The completer cohorts were older than those who provided no body-composition data during follow-up and contained proportionally more white and fewer black participants. A higher proportion of participants completed the high-protein, high-fat arm than did participants who completed the averageprotein, high-fat arm. 


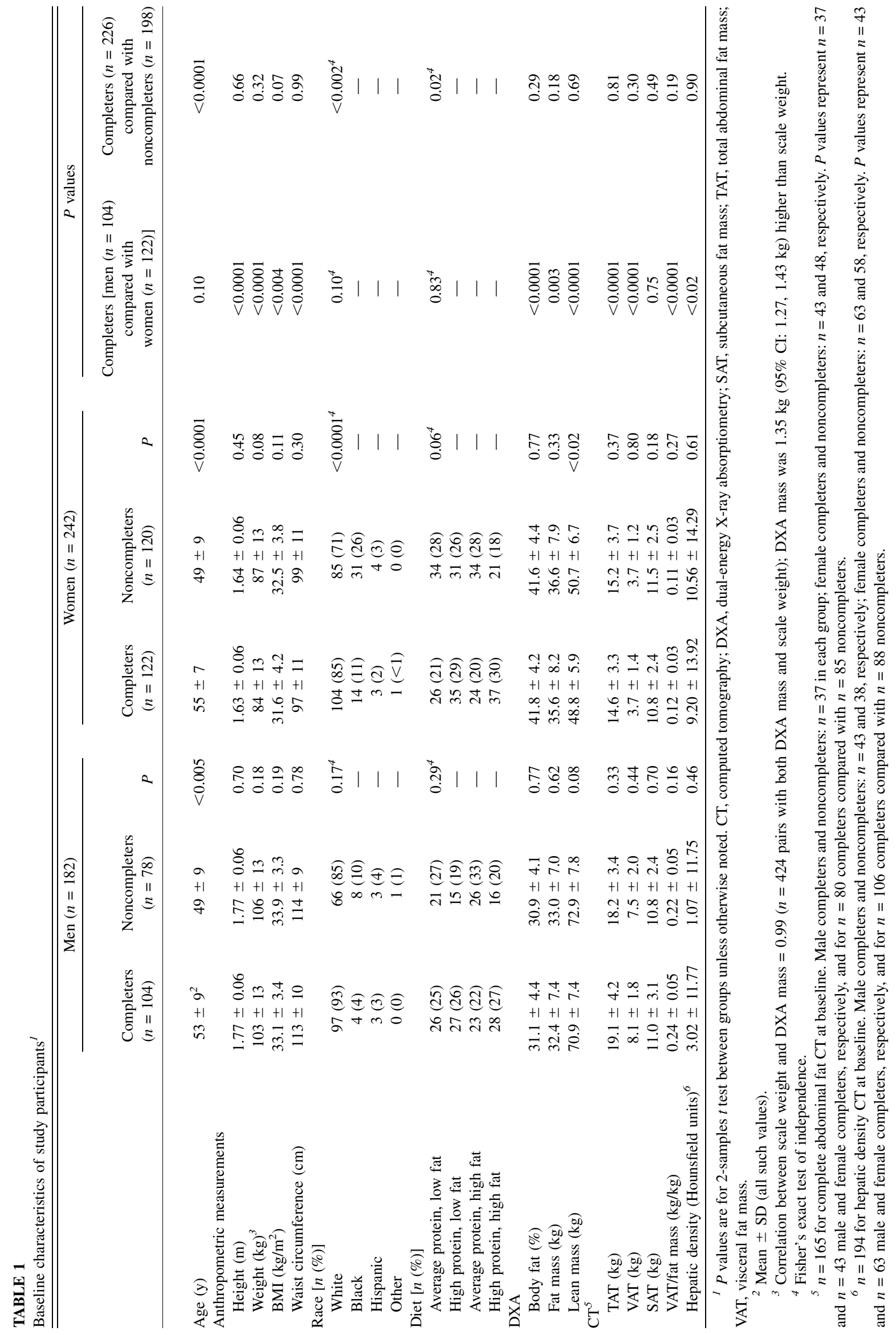




\section{Total fat mass and lean mass}

\section{Effects of diet type on fat and lean mass}

In total, 331 of 424 participants provided DXA measurements at 6 mo ( $22 \%$ imputed), and 236 participants provided DXA measurements at 2 y (44\% imputed). At $6 \mathrm{mo}$, total weight loss was $6.3 \pm 0.4 \mathrm{~kg}(-6.7 \%)$, with twice as much fat mass $(4.2 \pm$ $0.3 \mathrm{~kg} ;-12.4 \%)$ as lean mass $(2.1 \pm 0.3 \mathrm{~kg} ;-3.5 \%)$ lost when all diets were combined (all $P<0.0001$ compared with baseline values). By $2 \mathrm{y}$, participants had regained both fat and lean mass ( $\sim 40 \%$ of amount lost) but maintained a net weight loss of $3.8 \pm 0.4 \mathrm{~kg}(-4.1 \%)[2.4 \pm 0.3 \mathrm{~kg}(-6.8 \%)$ fat and $1.4 \pm 0.3 \mathrm{~kg}$ $(-2.3 \%$ ) lean mass] (all $P<0.0001$ compared with baseline values). Changes from baseline to 6 mo by diet type are shown in Figure 1. Fat loss or lean mass loss did not differ between diet assignments of high $(25 \%)$ and average $(15 \%)$ protein $(P \geq$ $0.10)$, high $(40 \%)$ and low $(20 \%)$ fat $(P \geq 0.34)$, or highest $(65 \%)$ and lowest $(35 \%)$ carbohydrate $(P \geq 0.27)$ at 6 mo. Between-diet differences remained nonsignificant at 2 y $(P \geq$ 0.23 ). In the dose-response test across amounts of carbohydrate, there was no linear trend across assigned carbohydrate amounts for fat or lean mass change at either time point $(P \geq 0.48)$. See "Supplemental data" in the online issue for a summary of nonimputed (completers only) data. The results for diet effects were similar to those in the primary intention-to-treat analysis except that the loss of lean mass at 6 mo was slightly greater in the average-protein than in the high-protein diet group and in the high-carbohydrate compared with in the low-carbohydrate diet group. These trends were not present at $2 \mathrm{y}$.

\section{Sex differences in fat and lean mass changes}

At baseline, men had lower percentage body fat and total-body fat mass and greater lean mass than did women (Table 1). In models that did not adjust for baseline values, men had greater losses of both fat and lean mass than did women with consideration of all diet groups together. After adjustment for baseline values, men $(4.4 \pm 0.3 \mathrm{~kg} ; n=182)$ and women $(4.0 \pm 0.3$; $n=226)$ lost similar amounts of fat mass $(P=0.37)$ and lean mass $(2.1 \pm 0.2$ and $2.0 \pm 0.2$, respectively; $P=0.64)$ at 6 mo. At $2 \mathrm{y}$, men had lost $2.8 \pm 0.4 \mathrm{~kg}$ fat mass and women had lost $2.1 \pm 0.3 \mathrm{~kg}$ fat mass $(P=0.20)$, with similar lean mass losses in both sexes (men: $1.5 \pm 0.3$; women: $1.3 \pm 0.2 \mathrm{~kg}$; $P=0.62$ ). The net result of these changes was a reduction of $2.8 \%$ body fat in men and $1.9 \%$ body fat in women at 6 mo (difference: $-0.9 \% ; P<0.001)$ and $1.8 \%$ body fat in men and $0.8 \%$ body fat in women at $2 \mathrm{y}$ (difference: $-1.0 \%$; 95\% CI: $-1.6 \%$, $-0.6 \% ; P<0.0001)$.

\section{Abdominal fat \\ Effects of diet type on visceral, subcutaneous, and total abdominal fat}

Changes from baseline to 6 mo in total abdominal, visceral, and subcutaneous abdominal fat by macronutrient amount are shown in Figure 2. In total, 117 of 165 participants provided CT data at 6 mo (29\% imputed), and 89 participants provided CT data at 2 y (46\% imputed). Total abdominal fat loss from baseline to 6 mo was $2.3 \pm 0.2 \mathrm{~kg}(-13.8 \%$ change from baseline), and most of this loss came from the subcutaneous compartment $(1.5 \pm 0.2 \mathrm{~kg} ;-13.6 \%)$ rather than the visceral compartment $(0.9 \pm 0.1 \mathrm{~kg} ;-16.1 \%)$ (all $P<0.0001$ compared with baseline values). By $2 \mathrm{y}$, participants had regained both subcutaneous and visceral adipose mass ( $\sim 40 \%$ of amount lost) but maintained a net loss of $1.3 \pm 0.2 \mathrm{~kg}$ total abdominal fat $(-7.8 \%)[0.5 \pm 0.1 \mathrm{~kg}(-8.9 \%)$ subcutaneous; $0.7 \pm 0.2 \mathrm{~kg}$ $(-6.3 \%)$ visceral] (all $P \leq 0.0002$ compared with baseline

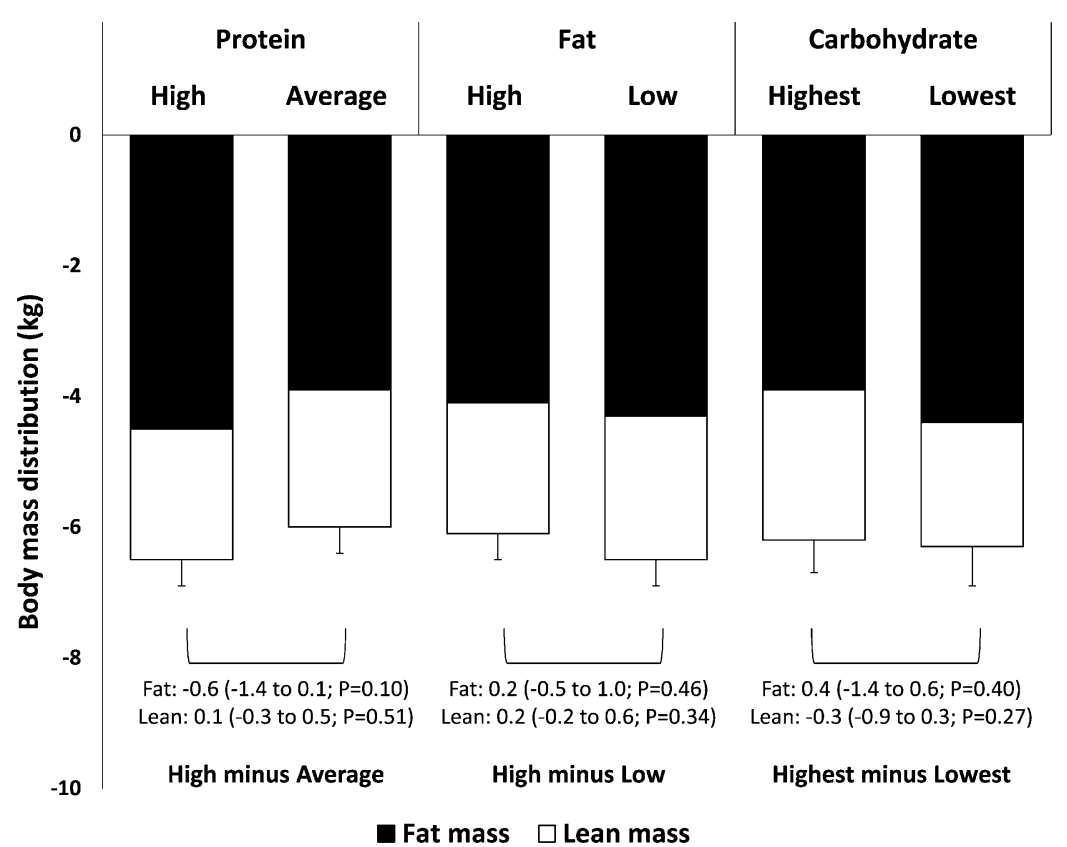

FIGURE 1. Mean ( \pm SEM) changes from baseline to 6 mo in lean and fat mass $(n=424$; intention-to-treat analysis) expressed by using generalized linear model ANOVA models that included the main effect of diet with baseline, age, sex, and site as covariates. $P$ values assessed the significance of the difference between the change on the 2 assigned amounts of each macronutrient (high protein $=25 \%$, average protein $=15 \%$; high fat $=40 \%$, low fat $=20 \%$; and highest carbohydrate $=65 \%$, lowest carbohydrate $=35 \%$ ), adjusted for multiple comparisons by using the Tukey-Kramer method. 


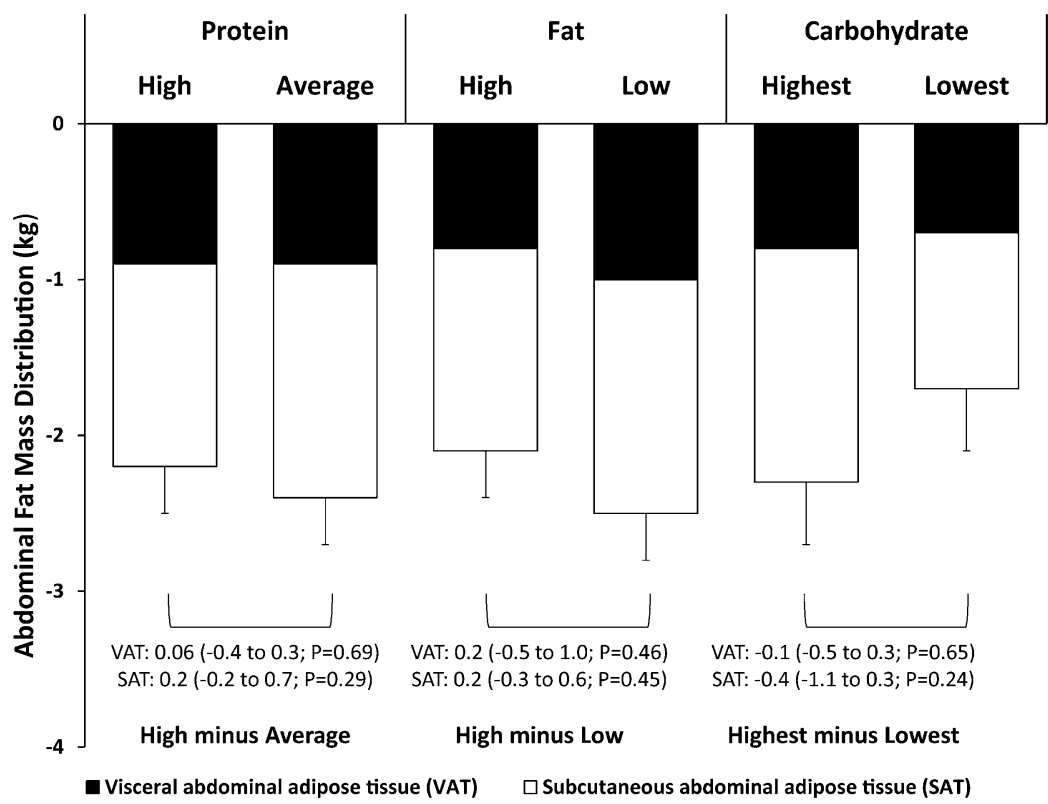

FIGURE 2. Mean $( \pm$ SEM) changes from baseline to 6 mo in visceral and subcutaneous abdominal fat ( $n=165$; intention-to-treat analysis) expressed by using generalized linear model ANOVA models that included the main effect of diet with baseline, age, sex, and site as covariates. $P$ values assessed the significance of the difference between the change on the 2 assigned amounts of each macronutrient $($ high protein $=25 \%$, average protein $=15 \%$; high fat $=$ $40 \%$, low fat $=20 \%$; and highest carbohydrate $=65 \%$, lowest carbohydrate $=35 \%$ ), adjusted for multiple comparisons using the Tukey-Kramer method .

values). There were no main effects of dietary protein or fat amount on total abdominal, subcutaneous, or visceral fat loss at either 6 mo $(P \geq 0.29-0.69)$ or 2 y ( $P \geq 0.84-0.94)$. Carbohydrate amount did not affect the change in any abdominal adipose compartment at either 6 mo or 2 y $(P \geq 0.24$ for highest compared with lowest; $P \geq 0.13$ for linear trend at both time points). See "Supplemental data" in the online issue for a summary of nonimputed (completers only) data. The results for diet effects were similar to those in the primary intention-to-treat analysis except that the loss of subcutaneous abdominal fat was slightly greater in the average-protein than in the high-protein group at 6 mo. These trends were not present at $2 \mathrm{y}$.

Sex differences in visceral, subcutaneous, and total abdominal fat changes

At baseline, men had more total abdominal and visceral fat and a greater waist circumference than did women (Table 1). Men lost more total abdominal fat (1.2 kg; $95 \% \mathrm{CI}: 0.3,2.0 \mathrm{~kg} ; P=0.006)$ and visceral fat $(1.0 \mathrm{~kg} ; 95 \% \mathrm{CI}: 0.6,1.3 \mathrm{~kg} ; P<0.0001)$ than did women at $6 \mathrm{mo}$, but there was no difference in the change in subcutaneous abdominal fat between sexes. By $2 \mathrm{y}$, the sex difference in visceral fat loss was smaller but still significant $(0.5 \mathrm{~kg}$ more in men than in women; $95 \% \mathrm{CI}: 0.1,0.9 \mathrm{~kg} ; P=0.01)$, but there was no significant difference in total abdominal fat loss $(P=0.08)$.

\section{Selectivity of diets for visceral fat reduction}

To test whether any of the diets reduced visceral fat more than would be expected from the reduction in total fat mass, we regressed the ratio of change in visceral fat to change in fat mass on the ratio of visceral fat to fat mass at baseline. This analysis included any participant who provided a measurement of both total mass and visceral fat mass at each time point and lost $5 \mathrm{~kg}$ total body weight with losses of both visceral and body fat (48 men and 53 women at 6 mo; 28 men and 30 women at 2 y).
Scatterplots of the baseline visceral fat/fat mass ratio compared with the ratio of $\Delta$ visceral fat/ $\Delta$ fat mass at both time points are shown in Figure 3. As expected, men had higher visceral fat/ fat mass than did women $(0.24 \pm 0.05$ compared with $0.11 \pm$ 0.03 , respectively; $P<0.0001$ ), and the correlation between the baseline visceral fat/fat mass ratio and the ratio of $\Delta$ visceral fat/ $\Delta$ fat mass was strong at 6 mo $(r=0.93$ for men and women; $P<$ $0.0001)$ and $2 \mathrm{y}(r=0.62$ for men; $r=0.83$ for women; $P \leq$ $0.0004)$. Pooled across all diets, $k$ was $1.19 \pm 0.04$ at 6 mo $\left(r^{2}=\right.$ $0.47)$ and $1.27 \pm 0.05$ at $2 \mathrm{y}\left(r^{2}=0.61\right)$, with no differences in $k$ between any pair of macronutrient amounts at 6 mo $(P \geq 0.39)$ or $2 \mathrm{y}(P \geq 0.17)$. For all men, $k$ at 6 mo was $1.15 \pm 0.06(n=$ $48)$; for women, $k$ was $1.32 \pm 0.07(n=51)$. At $2 \mathrm{y}, k$ was $1.20 \pm$ 0.05 for men $(n=28)$ and $1.53 \pm 0.10$ for women $(n=30)$. At both time points this sex difference was significant $(P \leq 0.04)$, which indicated that, given their baseline ratios of visceral to total fat mass, women lost more visceral fat than did men.

\section{Hepatic fat}

\section{Effects of diet type on hepatic fat}

In total, 147 of 194 participants provided hepatic density data at 6 mo (24\% imputed in the intention-to-treat analysis), and 112 participants provided hepatic density data at 2 y $(42 \%$ imputed). The CT-measured hepatic density change (measured in $\mathrm{HU}$ ), which is a marker for hepatic fat, by macronutrient amount is summarized in Figure 4. There were no significant correlations between alcohol intake (in g) and hepatic fat at baseline $(r=-0.009 ; n=191)$ or during follow-up $(r=0.045$, $n=147$ at $6 \mathrm{mo} ; r=-0.020, n=85$ at $2 \mathrm{y}$ ) in participants who provided complete diet and hepatic density data at each time point. The overall hepatic density change from baseline to 6 mo was $3.34 \pm 0.44$ HU $(\sim 60 \%$ change from baseline; $P<0.0001)$. By 2 y, the hepatic density remained $2.44 \pm 0.55$ 

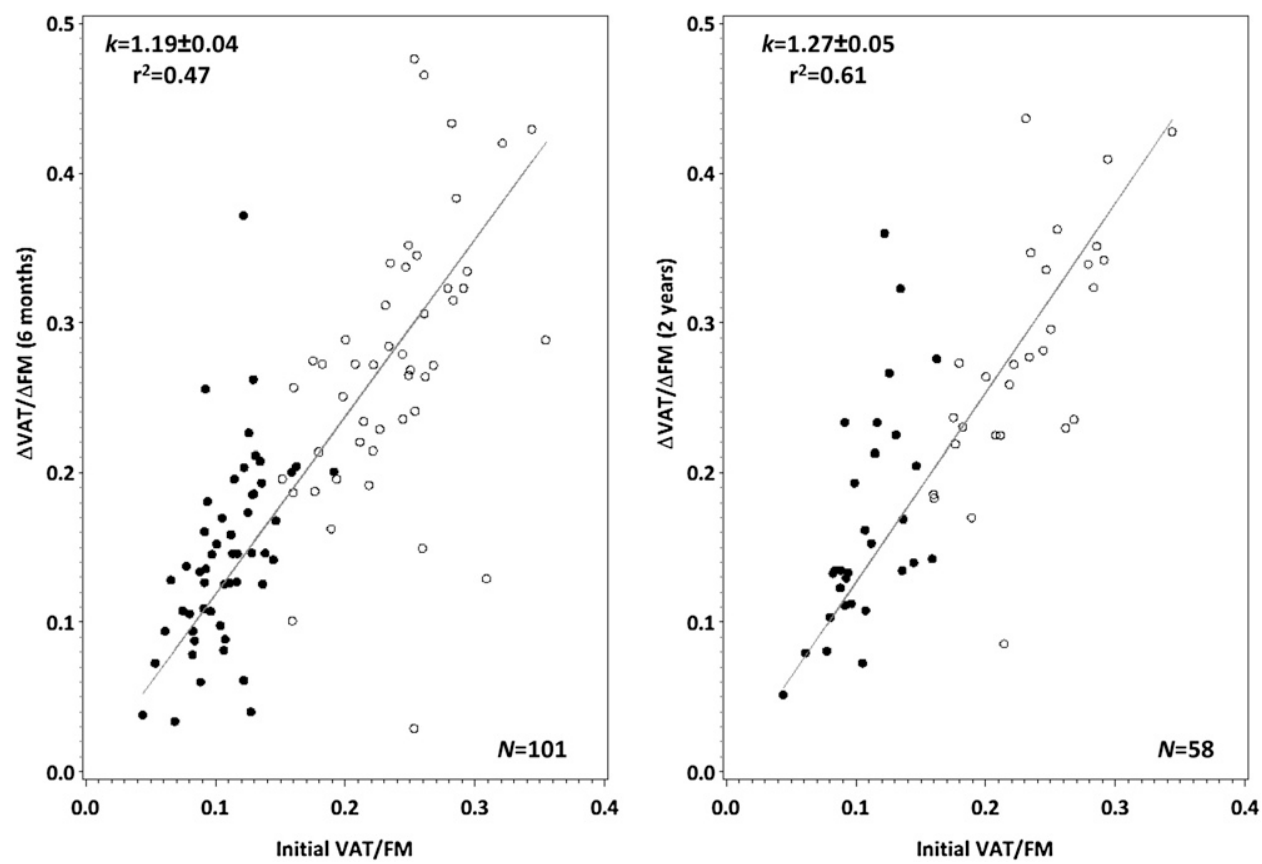

FIGURE 3. Linear regression of the ratio of the change in VAT to the change in FM compared with the ratio of initial VAT to FM across all 4 diets at 6 mo $(n=101)$ and at $2 \mathrm{y}(n=58)$ in men (open circles) and in women (filled circles). The analysis included only participants who lost both visceral adipose tissue and body fat (ie, $\triangle \mathrm{VAT}$ and $\triangle \mathrm{FM}<0$ ) and who lost $\geq 5 \mathrm{~kg}$ body weight. The line corresponds to the best-fit allometric relation to the weight-loss data, with $k=$ $1.19 \pm 0.04\left(r^{2}=0.47\right)$ at $6 \mathrm{mo}$ and $k=1.27 \pm 0.05\left(r^{2}=0.61\right)$ at $2 \mathrm{y} . \mathrm{FM}$, total fat mass; VAT, visceral fat mass.

HU higher than at baseline. There were no main effects of dietary protein or fat amounts on hepatic density changes at either 6 mo $(P \geq 0.32-0.84)$ or 2 y $(P \geq 0.79-0.87)$. Carbohydrate amount did not affect the change in hepatic density at either 6 mo or 2 y $(P \geq 0.28$ for highest compared with lowest; and $P \geq 0.65$ for linear trend at both time points). See "Supplemental data" in the online issue for a summary of nonimputed (completers only) data. The results for diet effects were similar to the primary intention-to-treat analysis.

\section{Sex differences in hepatic fat changes}

At baseline, men had a lower hepatic density than did women (by $7.70 \pm 1.91 \mathrm{HU} ; P<0.0001$; Table 1 ). Hepatic density had increased more in men than in women (by $2.28 \mathrm{HU}$; $95 \% \mathrm{CI}$ : $0.17,4.39 \mathrm{HU} ; P=0.04$ ) at $6 \mathrm{mo}$; however, adjustment for baseline, site, and age eliminated the sex effect $(-0.26 \mathrm{HU} ; 95 \%$ CI: $-2.09,1.57 \mathrm{HU} ; P=0.78)$. By $2 \mathrm{y}$, the sex difference in hepatic density change was no longer significant $(P \geq 0.73$ for both unadjusted and adjusted models).

\section{Dietary adherence}

\section{Self-report}

Self-reported nutrient intakes and biomarkers of nutrient intake at baseline, $6 \mathrm{mo}$, and $2 \mathrm{y}$ are presented in Table 2 . The dietary adherence in participants selected for the current

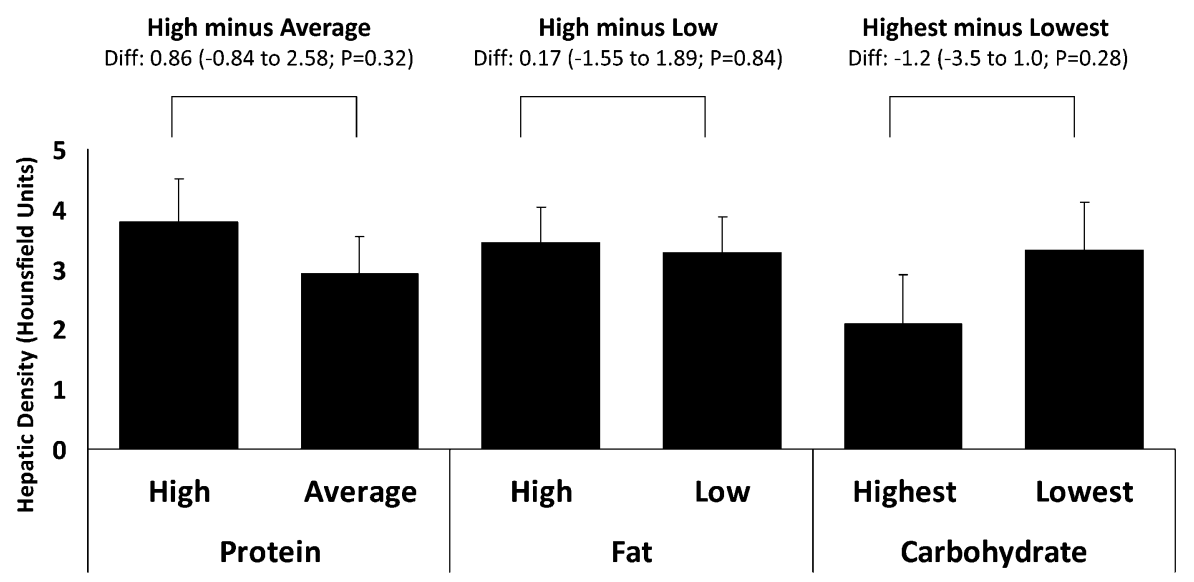

FIGURE 4. Mean ( \pm SEM) changes from baseline to 6 mo in hepatic fat $(n=194$; intention-to-treat analysis). Increases in hepatic density were produced by decreases in hepatic fat. Hepatic density was defined by the difference between liver and spleen density (Hounsfield units). Data were expressed by using generalized linear model ANOVA models that included main effect of diet with baseline, age, sex, and site as covariates. $P$ values assessed the significance of the difference between the change on the 2 assigned amounts of each macronutrient (high protein $=25 \%$, average protein $=15 \%$; high fat $=40 \%$, low fat $=$ $20 \%$; and highest carbohydrate $=65 \%$, lowest carbohydrate $=35 \%$ ), adjusted for multiple comparisons by using the Tukey-Kramer method. Diff, difference. 


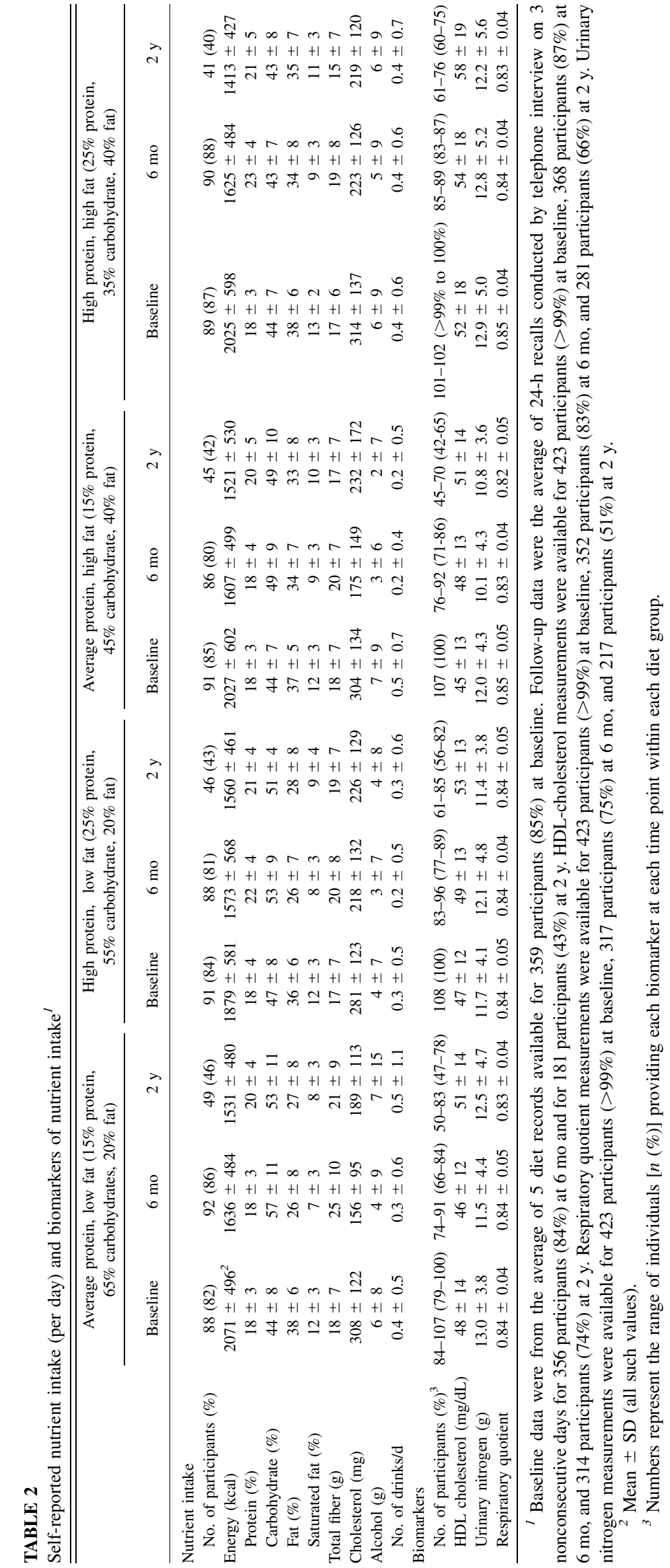


analyses was similar to that of the entire cohort as reported and discussed previously (30). Mean reported intakes at 6 mo and $2 \mathrm{y}$ did not reach target amounts for macronutrients (Table 2). We wished to see contrasts of $10 \%, 20 \%$, and $30 \%$ between amounts of protein, fat, and carbohydrate, respectively; however, selfreported dietary data suggested the observed contrasts were closer to $2 \%, 8 \%$, and $14 \%$ at $6 \mathrm{mo}$ and $1 \%, 7 \%$, and $10 \%$ at $2 \mathrm{y}$, respectively (Table 2 ).

\section{Biomarkers}

At the end of $6 \mathrm{mo}$, urinary nitrogen excretion decreased by $2.0 \pm 0.3 \mathrm{mg} / \mathrm{dL}$ in the $15 \%$-protein group $(P<0.0001)$, which corresponded to a $12-\mathrm{g} / \mathrm{d}$ reduction from baseline protein intake and was unchanged in the $25 \%$-protein group $(-0.1 \pm 0.3 \mathrm{mg} / \mathrm{dL}$, which was equal to a $<1-\mathrm{g} / \mathrm{d}$ reduction; $P=0.697)$. The difference between groups in 6-mo urinary nitrogen excretion was $1.8 \mathrm{mg} / \mathrm{dL}$ (95\% CI: 0.9, $2.8 \mathrm{mg} / \mathrm{dL} ; P<0.0001$, adjusted for baseline values), or $11 \mathrm{~g}$ protein/d. Because the reported energy intake by dietary recall at 6 mo was similar between arms $(\sim 1600 \mathrm{kcal} / \mathrm{d})$, dietary protein as a percentage of energy increased from $\sim 16.0 \%$ at baseline to $\sim 17.7 \%$ in the $15 \%$-protein group ( $P=0.023$ for change from baseline) and from $\sim 16.6$ to $20.0 \%$ in the $25 \%$-protein group $(P<0.0001$ ), which produced a $\sim 2-3 \%$ contrast in the percentage of protein energy between arms $(P=0.016)$ at 6 mo. HDL cholesterol, which is a biomarker of carbohydrate intake, was $3.1 \mathrm{mg} / \mathrm{dL}(95 \% \mathrm{CI}$ : $1.3,4.9 \mathrm{mg} / \mathrm{dL}$ ) lower after consumption of the $65 \%$-carbohydrate diet than after consumption of the $35 \%$-carbohydrate diet, which corresponded to a $\sim 10 \%$ difference in energy from carbohydrate. The RQ was 0.006 units lower in the $40 \%$-fat groups than in the $20 \%$-fat groups, which reflected a $\sim 2 \%$ difference in energy from fat (40), but this difference was not significant at 6 mo $(P=0.18$ on $\ln$-transformed values). Differences between macronutrient amounts at 6 mo were all in the directions predicted on the basis of macronutrient assignments, although target intakes were not fully achieved.

By $2 \mathrm{y}$, the calculated percentage of energy from protein by using urinary nitrogen excretion was not different between assigned $15 \%$ - and $25 \%$-protein diets (19.4\% compared with $18.9 \%$, respectively; $P=0.766$ ), and HDL cholesterol, which was reflective of the carbohydrate intake, also did not differ between 65\%- and 35\%-carbohydrate arms at 2 y (53.7 compared with $55.4 \mathrm{mg} / \mathrm{dL} ; P=0.12$ ). There was greater separation between the 2 fat amounts of a 0.01-unit lower RQ after consumption of the $40 \%$-fat diet than after consumption of the $20 \%$-fat diet (95\% CI: 0.0004, 0.0204; $P<0.039$ ), which corresponded to an $\sim 4 \%$ difference in energy.

\section{DISCUSSION}

In this study, reduction in total energy intake, rather than a particular macronutrient content of the diet, was the most important determinant of fat loss. This result is consistent with several previous trials that compared calorie-reduced high-protein ( $\sim 25-45 \%$ of energy) $(6,14,15,21,41-46)$ or high-fat $(\geq 40 \%)$ diets $(45,47-49)$ with high-carbohydrate $(\sim 55 \%)$ and low-fat $(<30 \%)$ diets.

Our primary intention-to-treat analysis showed no benefit of a $25 \%$-protein diet over a $15 \%$-protein diet for lean mass preservation. Other authors $(7,10,45)$ have shown higher protein promotes a greater loss of lean mass than do conventional low-fat diets, although a number of studies have shown that high-protein diets result in an equivalent loss of lean mass compared with high-carbohydrate diets in interventions $\leq 12$ mo $(6,9,11,12$, $21,43)$. The target protein intake for the $15 \%$-protein diets represented $\sim 0.7 \mathrm{~g} / \mathrm{kg}$ initial body weight $(64 \mathrm{~g} / \mathrm{d})$ and $\sim 1.1 \mathrm{~g} / \mathrm{kg}$ initial body weight $(103 \mathrm{~g} / \mathrm{d})$ for the $25 \%$-protein diets, which would have provided an $\sim 40-\mathrm{g}$ contrast in the daily protein intake if adherence was perfect. On the basis of urinary nitrogen excretion, the contrast was $\sim 13$ g between the high- and averageprotein groups at $6 \mathrm{mo}$, and the contrast was $\sim 3 \mathrm{~g}$ at $2 \mathrm{y}$.

We showed no main effect of the fat content of the diet on totalbody fat loss. Previous studies of body fat changes in response to varying macronutrient profiles have not shown a consistent benefit of fat and/or protein on body fat. In the 8 studies that used DXA, 3 studies showed an advantage for high-protein and high-fat diets over high-carbohydrate diets for fat loss $(8,11,50)$, and 5 studies showed equivalence $(6,14,15,42,46)$. In the 9 studies that used bioelectrical impedance, 5 studies showed advantages of high-protein and high-fat diets over high-carbohydrate diets (7, 9, $10,12,48)$, and 5 studies showed equivalence $(21,41,43,45,47)$. This equal distribution of positive and negative studies within both measures of body composition suggests that discrepant findings do not arise solely from differences in assessment methodology.

Our test for selectivity of visceral fat reduction provided no evidence for the preferential reduction of visceral fat after consumption of any diet, which supported the findings of Hallgreen and Hall (29) that visceral fat changes were explained by the allometry of visceral fat/fat mass and $\Delta$ visceral fat $/ \Delta$ fat mass. The absence of differences between any high and low or high and average macronutrient amounts argues that visceral fat loss was about what we would have expected from the fat loss after consumption of each diet. Our $k$ values at 6 mo and 2 y suggested that the loss of visceral fat and fat mass were related and consistent with a preferential visceral fat loss compared with a fat mass loss. These figures are in agreement with the value reported by Hallgreen and Hall (29) of $1.3 \pm 0.1$, which applied to a variety of weight-loss interventions such as bariatric surgery, caloric restriction with or without exercise, or exercise alone. Previous studies that favored high-protein over highcarbohydrate diets for visceral fat reduction $(8,11,15,21)$ did not account for the baseline ratio of visceral fat/fat mass when visceral fat loss was evaluated. In our study, women lost disproportionately more visceral fat than total fat on the basis of baseline amounts of these tissues than did men. Although the sex difference was significant, the group of individuals in which we tested the allometric theory was highly selected for visceral and total fat loss. We believe the overarching message is that visceral fat is preferentially reduced during weight loss in both sexes, and the greater visceral fat reductions in men were a result of their tendency to store more fat in this compartment.

With the use of noninvasive CT scans of liver and spleen densities as direct measures of hepatic fat content that have been validated against magnetic resonance spectroscopy, we showed that diet-induced weight loss, regardless of the macronutrient emphasized, reduced hepatic fat deposits in overweight and obese men and women. Very few studies of the effects of diet composition on intrahepatic fat have been performed in humans. It has been suggested that in a weight-stable or hypercaloric setting, higher-carbohydrate diets lead to increased de novo lipogenesis 
(51-53); and in the short-term ( $3 \mathrm{wk}$ ), higher-fat diets may increase intrahepatic fat (25). However, our results with 6 mo to $2 y$ of follow-up provided the first evidence, to our knowledge, that the macronutrient profile does not significantly influence changes in hepatic fat during weight loss. Consistent with our data, 2 other groups showed that weight reduction by using energy restriction and/or a structured exercise program reduced hepatic fat deposition. Larson-Myer et al (23) showed that intrahepatic fat was similarly reduced after $\sim 10 \%$ weight loss achieved via $25 \%$ calorie restriction, a structured exercise program, or a combination of calorie restriction and exercise over $6 \mathrm{mo}$, and Elias et al (24) showed that a 6-mo calorie restriction of 500-1000 kcal/d improved tomographic liver density. More work is needed to clarify the relations and interactions among energy deficit, the macronutrient profile, and intrahepatic fat.

The strengths of our study included the use of established reference methods to measure body composition (notably intrahepatic fat), a large sample size, 2 y of follow-up, and a population with nearly $40 \%$ men who, as a sex, are often underrepresented in weight-loss trials. Only 3 previous trials of macronutrients for weight loss had follow-ups of $\geq 1$ y $(6,11$, 12).

Despite the intensive behavioral counseling in our study, macronutrient targets were not fully met, which complicated the interpretation of our null result. We aimed to test a contrast in protein energy of $10 \%$ but achieved only an $\sim 3 \%$ contrast, which our trial was not powered to detect. Nevertheless, our 6-mo biomarker data are comparable with data reported in other dietary trials that targeted similar macronutrient differences. For example, the urinary nitrogen difference between our high- and average-protein arms was similar to that observed in the DIOGenes study $(2.1 \mathrm{~g} / \mathrm{d})$, which also targeted a $10 \%$ contrast in protein for weight-loss maintenance (54), and the difference in HDL cholesterol seen between our 65\%- and 35\%-carbohydrate diets after 6 mo was consistent with the contrasts in HDL cholesterol that compared a low-carbohydrate, high-fat diet (29.5\% carbohydrate) with a high-carbohydrate, low-fat diet (53.4\% carbohydrate) $(\sim 5 \mathrm{mg} / \mathrm{dL})(6)$ or a $50 \%$ - to a $40 \%$ carbohydrate diet (1.2 mg/dL) for weight loss (55). Our maximal difference in the RQ was not as pronounced in a previous study that compared a short-term $40 \%$-fat diet with a $20 \%$-fat diet with the goal of weight maintenance (RQ: $\sim 0.04$ ) (40). Notwithstanding the failure to meet intended targets, each of these trials achieved a large-enough contrast to detect macronutrient effects on body-weight outcomes, although the conditions of these trials were not directly comparable with ours.

Other comparative studies of weight loss and maintenance also failed to achieve target contrasts $(6,14,55-57)$, and our results are consistent with weight-loss trials that tested a $\sim 10 \%$ contrast in protein $(14,42)$ and with the largest study that examined a $\sim 20 \%$ contrast in fat (48). Studies that have shown macronutrient effects aimed to produce larger contrasts in protein $(8,11,12,50)$ or fat $(9,10)$, and thus it is possible that larger differences than those tested in our study are required for selective changes in body composition. However, diets that differ by $>10 \%$ protein and/or $20 \%$ fat would likely fall outside of the Institute of Medicine's Acceptable Macronutrient Distribution Range for at least one macronutrient (58).

Dropouts, diminished adherence, and gradual recidivism after the first few months are characteristic of all diet-induced weight- loss trials $(6,9-11,14,56,57,59)$. The dropout rate in our trial was smaller than in most trials, with $80 \%$ of participants returning for the 2-y weight measurement. DXA measurements were available for $78 \%$ of participants at $6 \mathrm{mo}$ and $56 \%$ of participants at $2 \mathrm{y}$, and CT measurements were available for $71 \%$ and $54 \%$ of participants, respectively. Only 2 trials have reported dietary intake beyond $1 \mathrm{y}(55,56)$, one study of which provided foods to the participants (55). In addition, trials of low-carbohydrate diets have reported a very low incidence of urinary ketones after 6 mo $(10,55,60)$, which suggests that, in most overweight people, a low intake of carbohydrate is not sustainable. Overall, these findings with respect to adherence to macronutrient goals suggest that participants in weight-loss programs gradually revert to their usual macronutrient intakes over time but may, nonetheless, be able to maintain some fat loss.

In conclusion, the POUNDS LOST trial provides evidence that, in a free-living setting, the loss of body fat, abdominal fat, and hepatic fat are dependent on calorie intake, and over distributions that are generally consistent with the Institute of Medicine's Acceptable Macronutrient Distribution Range, the macronutrient composition of the diet does not play a significant role in changes in body composition in overweight and obese individuals. However, despite our best efforts, adherence to diets high in protein, low in fat, or extremely low or high in carbohydrate proved difficult to achieve in our outpatient setting, which can be readily generalized to conditions under which such diets are commonly adopted. Across all macronutrient distributions tested, fat loss was greater than lean mass loss, more subcutaneous than visceral abdominal fat was lost, and hepatic fat was reduced significantly.

We thank the participants in the trial for their dedication and contribution to the research, and the following research staff members for their assistance in conducting the trial, preparation of some figures for the manuscript, and administrative support: Melissa McEnery-Stonelake and Benjamin Harshfield (Channing Laboratory, BWH) and Robin Post (PBRC).

The authors' responsibilities were as follows-RJdS: study conception and design, drafting of the manuscript, analysis and interpretation of data, statistical analysis, and critical revision of the manuscript for important intellectual content; GAB and FMS: obtainment of funding, study conception and design, interpretation of data, critical revision of the manuscript for important intellectual content, and supervision; VJC: analysis and interpretation of data, statistical analysis, critical revision of the manuscript for important intellectual content, and supervision, $\mathrm{KDH}$ : interpretation of data and critical revision of the manuscript for important intellectual content; MSL and CML: acquisition of data and critical revision of the manuscript for important intellectual content; NML: acquisition of data, administrative, technical, and material support, and critical revision of the manuscript for important intellectual content; and SRS: study conception and design, interpretation of data, critical revision of the manuscript for important intellectual content, and supervision. None of the authors had a conflict of interest.

\section{REFERENCES}

1. Ross R, Dagnone D, Jones PJ, Smith H, Paddags A, Hudson R, Janssen I. Reduction in obesity and related comorbid conditions after diet-induced weight loss or exercise-induced weight loss in men. A randomized, controlled trial. Ann Intern Med 2000;133:92-103.

2. Ross R, Janssen I, Dawson J, Kungl AM, Kuk JL, Wong SL, Nguyen-Duy TB, Lee S, Kilpatrick K, Hudson R. Exercise-induced reduction in obesity and insulin resistance in women: a randomized controlled trial. Obes Res 2004;12:789-98.

3. Redman LM, Heilbronn LK, Martin CK, Alfonso A, Smith SR, Ravussin E, Pennington CT. Effect of calorie restriction with or without exercise 
on body composition and fat distribution. J Clin Endocrinol Metab 2007; 92:865-72.

4. Kerksick C, Thomas A, Campbell B, Taylor L, Wilborn C, Marcello B, Roberts M, Pfau E, Grimstvedt M, Opusunju J, et al. Effects of a popular exercise and weight loss program on weight loss, body composition, energy expenditure and health in obese women. Nutr Metab (Lond) 2009;6:23.

5. Bray GA, Lovejoy JC, Most-Windhauser M, Smith SR, Volaufova J, Denkins Y, de Jonge L, Rood J, Lefevre M, Eldridge AL, et al. A 9-mo randomized clinical trial comparing fat-substituted and fat-reduced diets in healthy obese men: the Ole Study. Am J Clin Nutr 2002;76:928-34.

6. Gardner CD, Kiazand A, Alhassan S, Kim S, Stafford RS, Balise RR, Kraemer HC, King AC. Comparison of the Atkins, Zone, Ornish, and LEARN diets for change in weight and related risk factors among overweight premenopausal women: the A TO Z Weight Loss Study: a randomized trial. JAMA 2007;297:969-77.

7. McAuley KA, Hopkins CM, Smith KJ, McLay RT, Williams SM, Taylor RW, Mann JI. Comparison of high-fat and high-protein diets with a high-carbohydrate diet in insulin-resistant obese women. Diabetologia 2005;48:8-16.

8. Skov AR, Toubro S, Ronn B, Holm L, Astrup A. Randomized trial on protein vs carbohydrate in ad libitum fat reduced diet for the treatment of obesity. Int J Obes Relat Metab Disord 1999;23:528-36.

9. Brehm BJ, Seeley RJ, Daniels SR, D'Alessio DA. A randomized trial comparing a very low carbohydrate diet and a calorie-restricted low fat diet on body weight and cardiovascular risk factors in healthy women. J Clin Endocrinol Metab 2003;88:1617-23.

10. Yancy WS Jr, Olsen MK, Guyton JR, Bakst RP, Westman EC. A low-carbohydrate, ketogenic diet versus a low-fat diet to treat obesity and hyperlipidemia: a randomized, controlled trial. Ann Intern Med 2004;140:769-77.

11. Due A, Toubro S, Skov AR, Astrup A. Effect of normal-fat diets, either medium or high in protein, on body weight in overweight subjects: a randomised 1-year trial. Int J Obes Relat Metab Disord 2004;28: 1283-90.

12. Layman DK, Evans EM, Erickson D, Seyler J, Weber J, Bagshaw D, Griel A, Psota T, Kris-Etherton P. A moderate-protein diet produces sustained weight loss and long-term changes in body composition and blood lipids in obese adults. J Nutr 2009;139:514-21.

13. Layman DK, Boileau RA, Erickson DJ, Painter JE, Shiue H, Sather C, Christou DD. A reduced ratio of dietary carbohydrate to protein improves body composition and blood lipid profiles during weight loss in adult women. J Nutr 2003;133:411-7.

14. Keogh JB, Brinkworth GD, Noakes M, Belobrajdic DP, Buckley JD, Clifton PM. Effects of weight loss from a very-low-carbohydrate diet on endothelial function and markers of cardiovascular disease risk in subjects with abdominal obesity. Am J Clin Nutr 2008;87:567-76.

15. Noakes M, Keogh JB, Foster PR, Clifton PM. Effect of an energy-restricted, high-protein, low-fat diet relative to a conventional high-carbohydrate, low-fat diet on weight loss, body composition, nutritional status, and markers of cardiovascular health in obese women. Am J Clin Nutr 2005;81:1298-306.

16. Björntorp P. "Portal" adipose tissue as a generator of risk factors for cardiovascular disease and diabetes. Arteriosclerosis 1990;10:493-6.

17. Després JP, Lemieux I. Abdominal obesity and metabolic syndrome. Nature 2006;444:881-7.

18. Fox CS, Massaro JM, Hoffmann U, Pou KM, Maurovich-Horvat P, Liu CY, Vasan RS, Murabito JM, Meigs JB, Cupples LA, et al. Abdominal visceral and subcutaneous adipose tissue compartments: association with metabolic risk factors in the Framingham Heart Study. Circulation 2007;116:39-48

19. Wajchenberg BL. Subcutaneous and visceral adipose tissue: their relation to the metabolic syndrome. Endocr Rev 2000;21:697-738.

20. Mathieu P, Pibarot P, Larose E, Poirier P, Marette A, Despres JP. Visceral obesity and the heart. Int J Biochem Cell Biol 2008;40:821-36.

21. Miyashita Y, Koide N, Ohtsuka M, Ozaki H, Itoh Y, Oyama T, Uetake T, Ariga K, Shirai K. Beneficial effect of low carbohydrate in low calorie diets on visceral fat reduction in type 2 diabetic patients with obesity. Diabetes Res Clin Pract 2004;65:235-41.

22. Ross R. Effects of diet- and exercise-induced weight loss on visceral adipose tissue in men and women. Sports Med 1997;24:55-64.

23. Larson-Meyer DE, Newcomer BR, Heilbronn LK, Volaufova J, Smith SR, Alfonso AJ, Lefevre M, Rood JC, Williamson DA, Ravussin E. Effect of 6-month calorie restriction and exercise on serum and liver lipids and markers of liver function. Obesity (Silver Spring) 2008;16: 1355-62.

24. Elias MC, Parise ER, de Carvalho L, Szejnfeld D, Netto JP. Effect of 6-month nutritional intervention on non-alcoholic fatty liver disease. Nutrition 2010;26:1094-9.

25. van Herpen NA, Schrauwen-Hinderling VB, Schaart G, Mensink RP, Schrauwen P. Three weeks on a high-fat diet increases intrahepatic lipid accumulation and decreases metabolic flexibility in healthy overweight men. J Clin Endocrinol Metab 2011;96:E691-5.

26. Skov AR, Toubro S, Bulow J, Krabbe K, Parving HH, Astrup A. Changes in renal function during weight loss induced by high vs low-protein low-fat diets in overweight subjects. Int J Obes Relat Metab Disord 1999;23:1170-7.

27. Marks SJ, Moore NR, Clark ML, Strauss BJ, Hockaday TD. Reduction of visceral adipose tissue and improvement of metabolic indices: effect of dexfenfluramine in NIDDM. Obes Res 1996;4:1-7.

28. Smith SR, Zachwieja JJ. Visceral adipose tissue: a critical review of intervention strategies. Int J Obes Relat Metab Disord 1999;23: 329-35.

29. Hallgreen CE, Hall KD. Allometric relationship between changes of visceral fat and total fat mass. Int J Obes (Lond) 2008;32:845-52.

30. Sacks FM, Bray GA, Carey VJ, Smith SR, Ryan DH, Anton SD, McManus K, Champagne CM, Bishop LM, Laranjo N, et al. Comparison of weight-loss diets with different compositions of fat, protein, and carbohydrates. N Engl J Med 2009;360:859-73.

31. Champagne CM, Bogle ML, McGee BB, Yadrick K, Allen HR, Kramer TR, Simpson P, Gossett J, Weber J. Dietary intake in the lower Mississippi delta region: results from the Foods of our Delta Study. J Am Diet Assoc 2004;104:199-207.

32. Mensink RP, Katan MB. Effect of dietary fatty acids on serum lipids and lipoproteins. A meta-analysis of 27 trials. Arterioscler Thromb 1992;12:911-9.

33. Bingham SA, Cummings JH. Urine nitrogen as an independent validatory measure of dietary intake: a study of nitrogen balance in individuals consuming their normal diet. Am J Clin Nutr 1985;42:1276-89.

34. Westerterp KR. Food quotient, respiratory quotient, and energy balance. Am J Clin Nutr 1993;57:759S-64S; discussion 764S-65S.

35. Smith SR, De Jonge L, Volaufova J, Li Y, Xie H, Bray GA. Effect of pioglitazone on body composition and energy expenditure: a randomized controlled trial. Metabolism 2005;54:24-32.

36. Smith SR, Lovejoy JC, Greenway F, Ryan D, deJonge L, de la Bretonne J, Volafova J, Bray GA. Contributions of total body fat, abdominal subcutaneous adipose tissue compartments, and visceral adipose tissue to the metabolic complications of obesity. Metabolism 2001;50:425-35.

37. Kvist H, Chowdhury B, Grangard U, Tylen U, Sjostrom L. Total and visceral adipose-tissue volumes derived from measurements with computed tomography in adult men and women: predictive equations. Am J Clin Nutr 1988;48:1351-61.

38. Kvist H, Sjostrom L, Tylen U. Adipose tissue volume determinations in women by computed tomography: technical considerations. Int J Obes 1986;10:53-67.

39. Wadden TA, Berkowitz RI, Sarwer DB, Prus-Wisniewski R, Steinberg C. Benefits of lifestyle modification in the pharmacologic treatment of obesity: a randomized trial. Arch Intern Med 2001;161:218-27.

40. Abbott WG, Howard BV, Ruotolo G, Ravussin E. Energy expenditure in humans: effects of dietary fat and carbohydrate. Am J Physiol 1990; 258:E347-51.

41. Baba NH, Sawaya S, Torbay N, Habbal Z, Azar S, Hashim SA. High protein vs high carbohydrate hypoenergetic diet for the treatment of obese hyperinsulinemic subjects. Int J Obes Relat Metab Disord 1999; 23:1202-6.

42. Farnsworth E, Luscombe ND, Noakes M, Wittert G, Argyiou E, Clifton PM. Effect of a high-protein, energy-restricted diet on body composition, glycemic control, and lipid concentrations in overweight and obese hyperinsulinemic men and women. Am J Clin Nutr 2003;78: $31-9$.

43. Johnston CS, Tjonn SL, Swan PD. High-protein, low-fat diets are effective for weight loss and favorably alter biomarkers in healthy adults. J Nutr 2004;134:586-91.

44. Lean ME, Han TS, Prvan T, Richmond PR, Avenell A. Weight loss with high and low carbohydrate $1200 \mathrm{kcal}$ diets in free living women. Eur J Clin Nutr 1997;51:243-8.

45. Meckling KA, O'Sullivan C, Saari D. Comparison of a low-fat diet to a low-carbohydrate diet on weight loss, body composition, and risk 
factors for diabetes and cardiovascular disease in free-living, overweight men and women. J Clin Endocrinol Metab 2004;89:2717-23.

46. Gordon MM, Bopp MJ, Easter L, Miller GD, Lyles MF, Houston DK, Nicklas BJ, Kritchevsky SB. Effects of dietary protein on the composition of weight loss in post-menopausal women. J Nutr Health Aging 2008;12:505-9.

47. Jenkins DJ, Wong JM, Kendall CW, Esfahani A, Ng VW, Leong TC, Faulkner DA, Vidgen E, Greaves KA, Paul G, et al. The effect of a plant-based low-carbohydrate ("Eco-Atkins") diet on body weight and blood lipid concentrations in hyperlipidemic subjects. Arch Intern Med 2009;169:1046-54

48. Petersen M, Taylor MA, Saris WH, Verdich C, Toubro S, Macdonald I, Rossner S, Stich V, Guy-Grand B, Langin D, et al. Randomized, multi-center trial of two hypo-energetic diets in obese subjects: highversus low-fat content. Int J Obes (Lond) 2006;30:552-60.

49. Bradley U, Spence M, Courtney CH, McKinley MC, Ennis CN, McCance DR, McEneny J, Bell PM, Young IS, Hunter SJ. Low-fat versus low-carbohydrate weight reduction diets: effects on weight loss, insulin resistance, and cardiovascular risk: a randomized control trial. Diabetes 2009;58:2741-8.

50. Brehm BJ, Spang SE, Lattin BL, Seeley RJ, Daniels SR, D' Alessio DA. The role of energy expenditure in the differential weight loss in obese women on low-fat and low-carbohydrate diets. J Clin Endocrinol Metab 2005;90:1475-82.

51. Basciano H, Federico L, Adeli K. Fructose, insulin resistance, and metabolic dyslipidemia. Nutr Metab (Lond) 2005;2:5.

52. Faeh D, Minehira K, Schwarz JM, Periasamy R, Park S, Tappy L. Effect of fructose overfeeding and fish oil administration on hepatic de novo lipogenesis and insulin sensitivity in healthy men. Diabetes 2005; 54:1907-13. (Published erratum appears in Diabete. 2006;55:563.)

53. Davis JN, Le KA, Walker RW, Vikman S, Spruijt-Metz D, Weigensberg MJ, Allayee H, Goran MI. Increased hepatic fat in overweight Hispanic youth influenced by interaction between genetic variation in PNPLA3 and high dietary carbohydrate and sugar consumption. Am J Clin Nutr 2010;92:1522-7.

54. Larsen TM, Dalskov SM, van Baak M, Jebb SA, Papadaki A, Pfeiffer AF, Martinez JA, Handjieva-Darlenska T, Kunesova M, Pihlsgard M, et al. Diets with high or low protein content and glycemic index for weight-loss maintenance. N Engl J Med 2010;363:2102-13.

55. Shai I, Schwarzfuchs D, Henkin Y, Shahar DR, Witkow S, Greenberg I, Golan R, Fraser D, Bolotin A, Vardi H, et al. Weight loss with a lowcarbohydrate, Mediterranean, or low-fat diet. N Engl J Med 2008;359: $229-41$.

56. McManus K, Antinoro L, Sacks F. A randomized controlled trial of a moderate-fat, low-energy diet compared with a low fat, low-energy diet for weight loss in overweight adults. Int $\mathrm{J}$ Obes Relat Metab Disord 2001;25:1503-11.

57. Dansinger ML, Gleason JA, Griffith JL, Selker HP, Schaefer EJ. Comparison of the Atkins, Ornish, Weight Watchers, and Zone diets for weight loss and heart disease risk reduction: a randomized trial. JAMA 2005;293:43-53.

58. Institute of Medicine (US) Panel on Macronutrients and Standing Committee on the Scientific Evaluation of Dietary Reference Intakes. Macronutrients and healthful diets. Dietary reference intakes for energy, carbohydrate, fiber, fat, fatty acids, cholesterol, protein, and amino acids. Washington, DC: National Academies Press, 2005:769879.

59. Yancy WS Jr, Westman EC, McDuffie JR, Grambow SC, Jeffreys AS, Bolton J, Chalecki A, Oddone EZ. A randomized trial of a lowcarbohydrate diet vs orlistat plus a low-fat diet for weight loss. Arch Intern Med 2010;170:136-45.

60. Foster GD, Wyatt HR, Hill JO, McGuckin BG, Brill C, Mohammed BS, Szapary PO, Rader DJ, Edman JS, Klein S. A randomized trial of a low-carbohydrate diet for obesity. N Engl J Med 2003;348:2082-90. 